\title{
Role of USG \& MRI in Female Pelvic Masses with Histological Correlation in Post-Operative Patients
}

\author{
Yasmeen Usmani ${ }^{1}$, Pranav Bhartiya ${ }^{2}$, Mayank Kumar Shukla ${ }^{3}$ \\ 1,2,3 Department of Radio Diagnosis, L.L.R.M. Medical College, Meerut, Uttar Pradesh, India.
}

\section{ABSTRACT}

\section{BACKGROUND}

Adnexal masses are considered one of the most common disorders in gynaecology practice. One of the primary goals of imaging in the evaluation of adnexal masses is differentiating between malignant and benign lesions in order to direct patients to the appropriate treatment algorithm. We wanted to study the spectrum of varied nature of adnexal mass lesions, assess the relative role of USG and MRI in their detection, and compare them with the gold standard test, i.e., histopathological examination wherever possible.

\section{METHODS}

This prospective study was conducted among 74 patients who were clinically suspected to have adnexal lesions. USG and MRI using standard protocols were performed in all these patients with adnexal lesions and various features of adnexal lesions were identified.

\section{RESULTS}

Most commonly affected age group was 30 - 60 yrs. The major presenting complaints were lower abdominal pain and lump in the lower abdomen. In our study, the most common origin of adnexal lesions was from the either / both ovaries.

\section{CONCLUSIONS}

Sensitivity of MRI and USG for diagnosing malignancy of adnexal lesions is similar. However, due to better specificity and lower false positivity rate, higher sensitivity in detecting invasion of adjacent organs and organs of origin of lesions, MRI may be considered complimentary for optimal patient management and can be used in the assessment of problematic cases.

\section{KEY WORDS}

MRI, USG Pelvic Mass, Benign, Malignant
Corresponding Author: Dr. Mayank Kumar Shukla. Department of Radio Diagnosis, L.L.R..M Medical College, Meerut, Uttar Pradesh, India.

E-mail: mayankshuklanew@gmail.com

DOI: $10.14260 / j e m d s / 2020 / 754$

How to Cite This Article:

Usmani Y, Bhartiya P, Shukla MK, et al. Role of USG \& MRI in female pelvic masses with histological correlation in post-operative patients. J Evolution Med Dent Sci 2020;9(46):3439-3443, DOI: $10.14260 / \mathrm{jemds} / 2020 / 754$

Submission 27-07-2020,

Peer Review 24-09-2020,

Acceptance 30-09-2020,

Published 16-11-2020.

Copyright (c) 2020 JEMDS. This is an open access article distributed under Creative Commons Attribution License [Attribution 4.0 International (CC BY 4.0)] 


\section{BACKGROUND}

Pelvic mass is a common presentation of gynaecological pathologies. Ultrasound remains the first line imaging modality for the female pelvis. MRI should be considered for the evaluation of adnexal pathology when sonographic characteristics are not definitive to determine the origin of the mass and to determine the likelihood of malignancy. ${ }^{1}$ This study was conducted with a view to find out the relative role of MRI \& USG in adnexal masses and its correlation with gold standard test, i.e., histopathological examination in operated patients. ${ }^{2}$ The cut off value of CA-125 level for classifying benign and malignant lesions was taken as 35 IU / ML. The cut off value of size of lesions for classifying benign and malignant lesions was taken as $7 \mathrm{~cm}^{3}$

\section{METHODS}

Our main source of data for the study was clinically suspected patients from the Department of Obstetrics \& Gynaecology LLRM Medical College, Meerut coming to the Department of Radiodiagnosis, LLRM Medical College, Meerut, for imaging study for the period of Jan 2018 to Nov 2018.

All patients with clinically suspected adnexal masses when referred to the Department of Radio Diagnosis for the same examined with trans abdominal USG / trans vaginal sonography and a 1.5 Tesla MRI using abdominal surface coils. Contrast will be given as and when necessary. The patient will be followed up to co relate the findings with clinical outcome or operative findings. ${ }^{4,5}$

The study was conducted on 74 patients focussing mainly on clinically suspected to have adnexal lesions \& sonographically indeterminate adnexal masses. ${ }^{6}$

The subjects of this study were patients who are clinically suspected to have adnexal lesions and underwent USG and MRI. The study will be performed on all patients after written informed consent. ${ }^{7}$

The MR images were evaluated without knowledge of the surgical or pathologic findings. The MR imaging features were then correlated with the USG findings and pathologic findings wherever possible. ${ }^{8}$ The imaging features documentation included the number of adnexal masses per patient, origin of lesion (ovarian, tubal, tuboovarian or extraovarian), lesion shape, lesion size, and content of lesion (solid only, complex solid-cystic, and cystic only).9,10 If a wall and internal septae could be identified, its thickness, character, and enhancement will be noted. The septal characteristics including the number, thickness, character (smooth or irregular), and enhancement of the septa were recorded. Any vegetation appearing on the wall or the septum of the lesion were measured and noted. Tissues with low signal intensity on T2-weighted MR images (i.e., $\leq$ signal intensity of skeletal muscle) were also noted.11,12 Such low-signal-intensity tissue is indicative of fibrous tissue. Patients who were not operated or lost to follow-up, the imaging features were described. USG is done before or after the examination of MRI and postoperative histopathological findings were noted wherever possible. The cut off value of CA125 level for classifying benign and malignant lesions was taken as 35 IU / ML. The cut off value of size of lesions for classifying benign and malignant lesions was taken as 7 cm. 13,14 $^{2}$

\section{Equipment}

- Magnetom symphony a tin system (Phillips) with magnetic field strength of 1.5 Tesla.

- Gadolinium based contrast material if needed.

- Philips ClearVue550 ultrasound machine.

\section{Inclusion Criteria}

- All patients with clinically suspected adnexal masses.

- Patients of 30 - 60 years age group.

\section{Exclusion Criteria}

- All Patients having cardiac pacemakers, prosthetic heart valves, cochlear implants or any metallic implants. ${ }^{15}$

- Patients having history of claustrophobia.

- All patients who do not consent to be a part of the study.

\section{Study Design}

Comparative observational study for determining the efficacy of Ultrasound and MRI for detection of adnexal masses in comparison to histopathological examination of postoperative masses. ${ }^{16,17}$

\section{Gold Standard Investigation}

The gold standard test applied here is histopathological examination which is confirmed by immunohistochemistry. 18

\section{Statistical Analysis}

Parameters of validity of the test such as sensitivity, specificity and diagnostic accuracy of ultrasound and MRI compared with histopathological examination. ${ }^{19,20}$

\section{RESULTS}

A total of 81 adnexal lesions was detected in 74 patients on MRI. Out of 74 patients, 37 patients (39 lesions) were operated and these findings on MRI and USG were correlated with postoperative histopathological findings. Out of remaining 37 patients, 18 patients (21 lesions) were followed up with either USG or MRI for change in size / characteristics / stability of lesions with or without treatment. ${ }^{21}$ Remaining 19 patients were not operated and were also lost to follow up and were analysed only on basis of imaging findings. The most common symptom observed in 74 patients was pain abdomen (75\%) followed by abdominal distension (60\%) and bleeding per vaginum (56\%). ${ }^{22,}{ }^{23}$ Constipation and dysuria were also seen in few patients. The most common age group encountered was 30 - 60 yrs. and $54 \%$ lesions ( 40 out of 74 patients) were seen in this age group. Out of total 12 malignant adnexal lesions, 9 were seen $>40 \mathrm{yrs}$. and 3 were $<40$ yrs. Investigation of CA125 in 35 patients with adnexal lesions, revealed that out of 6 patients with malignant lesions, 5 patients had raised (> 35 IU 
/ ML) CA-125 level (80 \%).24,25 One patient with serous cystadenocarcinoma had low level of CA-125. Out of total 39 benign lesions 35 had low level (89.7\%) and 4 had raised level (> 35 IU / ML) of CA-125 (10.2\%). ${ }^{26}$ The benign adnexal lesions with raised CA-125 were 1 endometriomas and 3 cystadenomas.

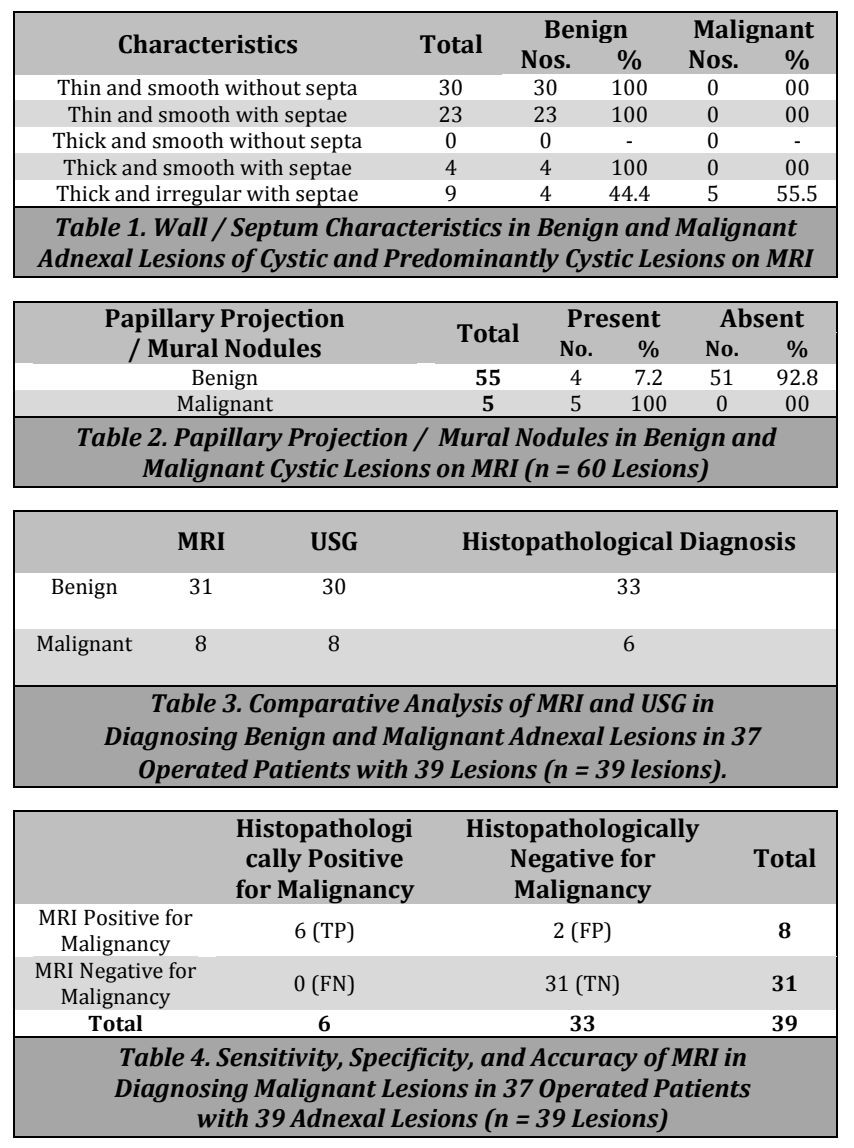

Sensitivity $=(\mathrm{TP} / \mathrm{TP}+\mathrm{FP}) \times 100=75 \%$, Specificity $=(\mathrm{TN} /$ $\mathrm{TN}+\mathrm{FP}) \times 100=93.9 \%$, Accuracy $=(\mathrm{TP}+\mathrm{TN} / \mathrm{TP}+\mathrm{TN}+\mathrm{FP}$ + FN) $\times 100=94.8 \%$.

\begin{tabular}{|c|c|c|c|}
\hline & $\begin{array}{l}\text { Histopathologically } \\
\text { positive for } \\
\text { Malignancy }\end{array}$ & $\begin{array}{l}\text { Histopathologically } \\
\text { Negative for } \\
\text { Malignancy }\end{array}$ & Total \\
\hline $\begin{array}{l}\text { USG Positive } \\
\text { for Malignancy }\end{array}$ & 6 (TP) & $2(\mathrm{FP})$ & 8 \\
\hline $\begin{array}{l}\text { USG Negative } \\
\text { for Malignancy }\end{array}$ & $0(\mathrm{FN})$ & $30(\mathrm{TN})$ & 30 \\
\hline Total & 6 & 32 & 38 \\
\hline \multicolumn{4}{|c|}{$\begin{array}{c}\text { Table 5. Sensitivity, Specificity and Accuracy of USG in Diagnosing } \\
\text { Malignant Adnexal Lesions in } 37 \text { Operated Patients with } 38 \text { Adnexal } \\
\text { Lesions ( } n=38 \text { Lesions) }\end{array}$} \\
\hline
\end{tabular}

Sensitivity $=(\mathrm{TP} / \mathrm{TP}+\mathrm{FP}) \times 100=75 \%$, Specificity $=(\mathrm{TN} / \mathrm{TN}$ $+\mathrm{FP}) \times 100=93.7 \%$, Accuracy $=(\mathrm{TP}+\mathrm{TN} / \mathrm{TP}+\mathrm{TN}+\mathrm{FP}+\mathrm{FN})$ $\mathrm{x} 100=94.7 \%$.

\section{DISCUSSION}

On MRI of 74 patients with adnexal lesions, 81 lesions were detected out of which 78 were detected on USG and 81 were detected on MRI. ${ }^{29}$ On imaging studies, 69 lesions were benign and 12 malignant. Out of these 69 benign lesions, 23 (33.3\%) lesions were $<7 \mathrm{~cm}$ and $46(66.6 \%)$ were $>7 \mathrm{~cm}$. Out of 12 malignant lesions 4 (33.3\%) lesions were $<7 \mathrm{~cm}$ and 8 (66.6 $\%$ ) were $>7 \mathrm{~cm} \cdot{ }^{30}$

Based on type of content 15 lesions had solid content, out of which 13 (86.6\%) were benign and 2 (13.3\%) were malignant. 14 lesions had complex solid cystic content, out of which 5 (35.7 \%) were benign and 9 (64.2\%) were malignant. ${ }^{31-36} 52$ lesions were cystic, out of which 51 (98.0\%) were benign and $1(1.9 \%)$ were malignant. In benign lesions, fat plane was maintained in all $(100 \%)$ cases whereas, in malignant, $2(16.6 \%)$ lesions had loss of fat plane while it was maintained in 10 (83.3\%) cases.

The lesions were cystadenoma / cystadenofibroma (23.4 $\%$ ), endometriomas (14.8\%) and subserosal / broad ligament leiomyomas / intramural leiomyomas with large exophytic component (12.3\%), haemorrhagic cysts (9.8\%), dermoid cysts (6.1\%) infective tuboovarian masses (8.6\%), simple cyst (4.8\%), Krukenberg tumour (4.9\%), and cystadenocarcinoma (6.1\%), carcinoma cervix with large exophytic component (2.4 \%). $37-40$.

In comparison with the gold standard test, i.e., histopathological examination of specimen obtained from laparotomy / laparoscopy of adnexal masses, the sensitivity, specificity and accuracy of MRI in diagnosing malignancy in 37 operated patients with 39 adnexal lesions were $75 \%$, $93.9 \%$ and $94.8 \%$ respectively (Table 4 ). In the present study, the sensitivity, specificity and accuracy of USG in diagnosing malignancy in 37 operated patients with 38 adnexal lesions were $75 \%, 93.7 \%$ respectively. Conclusively the sensitivity of MRI and USG for diagnosing malignancy of adnexal lesions is similar (75 \%) (Table 5). ${ }^{41}$

\section{CONCLUSIONS}

MRI may be considered as complimentary for optimal patient management since it has better specificity and lower false positivity rate, higher sensitivity in detecting invasion of adjacent organs and organs of origin of lesions.

Cases with pelvic masses can be resolved promptly by the referring physician and the radiologist through prompt collaboration. As the diagnosis should be assessed in the shortest time with the greatest care and accuracy, it is necessary to choose the appropriate available examinations, thus reducing the time needed to establish a diagnosis and decreasing the number of examinations required. Ultrasound remains the main diagnostic imaging modality prior to treatment. Improved detection and characterization of pelvic mass contribute to better diagnostic accuracy and consequently reduction of false-positive findings and invasive procedures, which leads to a significant reduction of morbidity and mortality from pelvic masses. 42

MRI should be considered for evaluation of adnexal pathology when sonographic characteristics are not definitive in determining the origin of mass as well as to determine the likelihood of malignancy. Histopathological examination of specimen obtained from laparotomy / laparoscopy of adnexal mass is the gold standard for confirming the diagnosis. However, no single diagnostic aid in itself is sufficient in determining the pathological adnexal masses. Hence, a multifaceted diagnostic approach should be used for a definitive diagnosis and management of adnexal mass. 
Data sharing statement provided by the authors is available with the full text of this article at jemds.com.

Financial or other competing interests: None.

Disclosure forms provided by the authors are available with the full text of this article at jemds.com.

\section{REFERENCES}

[1] Bhagde AD, Jani SK, Patel MS, et al. An analytical study of 50 women presenting with an adnexal mass. Int J Reprod Contracept Obstet Gynecol 2017;6(1):262-5.

[2] Thawait SK, Batra K, Johnson SI, et al. Magnetic resonance imaging evaluation of non-ovarian adnexal lesions. Clin Imaging 2016;40(1):33-45.

[3] Karnik A, Tembey RA, Mani S. Value of MRI in characterizing adnexal masses. J Obstet Gynaecol India 2015;65(4):259-66.

[4] Gibert BS, Sakly H, Ballester M et al. Diagnostic value of MR imaging in the diagnosis of adnexal torsion. Radiology 2016;279(2):461-70.

[5] Anthoulakis C, Nikoloudis N. Pelvic MRI as the "gold standard" in the subsequent evaluation of ultrasound in determinate adnexal lesions: a systematic review. Gynecol Oncol 2014;132(3):661-8.

[6] Haggerty AF, Hagemann AR, Chu C, et al. Correlation of pelvic magnetic resonance imaging diagnosis with pathology for indeterminate adnexal masses. Int J Gynecol Cancer 2014;24(7):1215-21.

[7] Kao LY, Scheinfeld MH, Chernyak V, et al. Beyond ultrasound: CT and MRI of ectopic pregnancy. Am J Roentgenol 2014;202(4):904-11.

[8] Wasnik AP, Menias C, Platt JF, et al. Multimodality imaging of ovarian cystic lesions: review with an imaging based algorithmic approach. World J Radiol 2013;5(3):113-25.

[9] Dwivedi AND, Jain S, Shukla RC, et al. MRI is a state of art imaging modality in characterization of indeterminate adnexal masses. J Biomedical Science and Engineering 2013;6:309-13.

[10] Mahajan M, Kuber R, Chaudhari KR, et al. MR imaging of carcinoma cervix. Indian J Radiol Imaging 2013;23(3):247-52.

[11] Valentini AL, Gui B, Micco M, et al. Benign and suspicious ovarian masses-MR imaging criteria for characterization: pictorial review. J Oncol 2012;2012:481806.

[12] Haldorsen LS, Salvesen HB. Staging of endometrial carcinomas with MRI using traditional and novel MRI techniques. Clin Radiol 2012;67(1):2-12.

[13] Chilla B, Hauser N, Singer G, et al. Indeterminate adnexal masses at ultrasound: effect of MRI imaging findings on diagnostic thinking and therapeutic decisions. Eur Radiol 2011;21(6):1301-10.

[14] Brown DL, Dudiak KM, Laing FC. Adnexal masses: US characterization and reporting. Radiology 2010;254(2):342-54.

[15] Lalwani N, Shanbhogue AKP, Vikram R, et al. Current update on borderline ovarian neoplasms. AJR Am J Roentgenol 2010;194(2):330-6.

[16] Ljubic A, Bozanovic T, Vilendecic Z. Sonographic evaluation of benign pelvic masses. Donald School Journal of Ultrasound in Obstetrics and Gynecology 2009;3(2):58-68.

[17] Kim MY, Rha SE, Oh SN, et al. MR Imaging findings of hydrosalpinx: a comprehensive review. Radiographics 2009;29(2):495-507.

[18] Joshi M, Ganesan K, Munshi HN, et al. Ultrasound of adnexal masses. Semin Ultrasound CT MR 2008;29(2):7297.

[19] Guerra A, Cunha TM, Félix A. Magnetic resonance evaluation of adnexal masses. Acta Radiol 2008;49(6):700-9.

[20] Van Holsbeke C, Domali E, Holland TK, et al. Imaging of gynecological disease (3): clinical and ultrasound characteristics of granulosa cell tumors of the ovary. Ultrasound Obstet Gynecol 2008;31(4):450-6.

[21] Sala E, Wakely S, Senior E, et al. MRI of malignant neoplasm of the uterine corpus and cervix. Am J Roentgenol 2007;188(6):1577-87.

[22] Sherer DM, Gorelick C, Gabbur N, et al. Transvaginal sonographic findings of a large intramural uterine hematoma associated with iatrogenic injury sustained at termination of pregnancy. Ultrasound Obstet Gynecol 2007;30(1):110-3.

[23] Van Calster B, Timmerman D, Bourne T, et al. Discrimination between benign and malignant adnexal masses by specialist ultrasound examination versus serum CA-125. J Natl Cancer Inst 2007;99(22):1706-14.

[24] Rajkotia K, Veeramani M, Macura KJ. Magnetic resonance imaging of adnexal masses. Topics in Magnetic Resonance Imaging 2006;17(6):379-97.

[25] Kinkel K, Frei KA, Balleyguier C, et al. Diagnosis of endometriosis with imaging: a review. Eur Radiol 2006;16(2):285-98.

[26] Tamai K, Koyama T, Saga T, et al. MR features of physiologic and benign conditions of the ovary. Eur Radiol 2006;16(12):2700-11.

[27] Byun JY. MR imaging findings of ovarian cystadenofibroma: clues for making the differential diagnosis from ovarian malignancy. Korean J Radiol 2006;7(3):153-5.

[28] Adusumilli S, Hussain HK, Caoili EM, et al. MRI of sonographically indeterminate adnexal masses. AJR Am J Roentgenol 2006;187(3):732-40.

[29] Jung SE, Rha SE, Lee JM, et al. CT and MRI findings of sex cord-stromal tumor of the ovary. AJR Am J Roentgenol 2005;185(1):207-15.

[30] van Rijswijk CSP, Geirnaerdt MJA, Hogendoorn PCW, et al. Soft-tissue tumors: value of static and dynamic gadopentetate dimeglumine-enhanced MR imaging in prediction of malignancy. Radiology 2004;233(2):493502.

[31] Sohaib SAA, Sahdev A, Trappen PV, et al. Characterization of adnexal mass lesions on MR imaging. Am J Roentgenol 2003;180(5):1297-304.

[32] Takeuchi M, Matsuzaki K, Kusaka M, et al. Ovarian cystadenofibromas: characteristic magnetic resonance findings with pathologic correlation. J Comput Assist Tomogr 2003;27(6):871-3.

[33] Togashi K. Ovarian cancer: the clinical role of US, CT, and MRI. Eur Radiol 2003;13 Suppl 4:L87-104. 
[34] Funt SA, Hann LF. Detection and characterization of adnexal masses. Radiol Clin North Am 2002;40(3):591608.

[35] Outwater EK, Siegelman ES, Hunt JL. Ovarian teratomas: tumor types and imaging characteristics. Radiographics 2001;21(2):475-90.

[36] Jeong YY, Outwater EK, Kang HK. Imaging evaluation of ovarian masses. Radiographics 2000;20:1445-70.

[37] Leung WT, Hricak H. MRI in evaluation of gynaecological diseases. In: Callen PW, ed. Ultrasonography in obstetrics and gynaecology. $4^{\text {th }}$ edn. Philadelphia: WB Saunders 2000; p. 935.

[38] Murase E, Siegelman ES, Outwater EK, et al. Uterine leiomyomas: histopathologic features, MR imaging findings, differential diagnosis and treatment. Radiographics 1999;19(5):1179-97.
[39] Iizuka M, Igarashi $M, A b e ~ Y$, et al. Chemical assay of iron in ovarian cysts: a new diagnostic method to evaluate endometriotic cysts. Gynecol Obstet Invest 1998;46(1):58-60.

[40] Kim SH, Kim WH, Park KJ, et al. CT and MR findings of Krukenberg tumors: comparison with primary ovarian tumors. J Comput Assist Tomogr 1996;20(3):393-8.

[41] Hricak H, Finck S, Honda G, et al. MR imaging in the evaluation of benign uterine masses: value of gadopentetate dimeglumine- enhanced T1-weighted images. AJR Am J Roentgenol 1992;158(5):1043-50.

[42] Nishi M, Akamatsu N, Sekiba K. Magnetic resonance imaging of the ovarian cyst: its diagnostic value of endometrial cyst. Med Prog Technol 1990;16(4):201-12. 